\title{
Review of Restraint Data in a Residential Treatment Center for Adolescent Females
}

\section{Brian D. Leidy · Jeffrey J. Haugaard • \\ Michael A. Nunno · Jason K. Kwartner}

Published online: 29 September 2006

(C) Springer Science+Business Media, LLC 2006

\section{Erratum to: Child Youth Care Forum \\ DOI 10.1007/s10566-006-9021-z}

The authors are aware of the redundancy in the first sentence of the abstract. An effort was made to correct it prior to publication but without success.

The online version of the original article can be found at http://dx.doi.org/10.1007/s10566-006-9021-z

B. D. Leidy $(\bowtie) \cdot$ M. A. Nunno $\cdot$ J. K. Kwartner

Cornell University, Beebe Hall, Ithaca, NY 14850, USA

e-mail: bl15@cornell.edu 